\title{
Biografía
}

\section{Dr. Gonzalo Cubero Otoya}

El doctor Cubero fue un personaje extraordinario en la sociedad costarricense y representó uno de los íconos del siglo XX, no solo como médico, sino como hombre culto de múltiples facetas.

Sin duda alguna, él fue una de las personalidades que abarcó el saber total y que disfrutaba la vida de muy distintas maneras, pudiendo hablarse de sus dotes de cazador destacado (capaz de darle en el aire a una moneda de cincuenta céntimos), o de que fue jinete hasta su vejez, o de que como aviador pionero recorría el país aterrizando en playas desconocidas, o de su virtud de hablar seis idiomas (español, alemán, inglés, francés, italiano y portugués), o de su desempeño como embajador distinguido de Costa Rica en Alemania, Austria y Noruega.

Además de todas esas virtudes, el doctor Cubero le dio realce a la medicina nacional, no solamente con su honradez y enorme capacidad de trabajo (en el Hospital San Juan de Dios siempre estuvo entre los cirujanos que más operaciones hacían por año), sino también con sus dotes de gran maestro, con las que supo educar a muchos de sus colegas jóvenes e inventar técnicas quirúrgicas e implementos médicos que todavía llevan su nombre, como la pinza Cubero (registrada en The Year Book of General Surgery), en la que utilizaba tres hilos sin necesidad de hacer nudo (según él, se trataba simplemente de un triple nudo de chancho aprendido desde sus correrías de infancia).

Gonzalo Cubero Otoya nació el 1 de julio de 1903 y pertenecía a una familia de la sociedad josefina, cuyo abuelo materno había fundado el Barrio Otoya y cedido el terreno para la construcción del Parque Bolívar. A los siete años, y gracias a la capacidad económica de su familia, fue a vivir a Lausana, con lo que consiguió aprender francés. En esa ciudad suiza su familia recibía periódicamente al joven Ricardo Moreno, quien estudiaba medicina en la Universidad de Ginebra.

El niño Cubero tuvo en Suiza dos experiencias que lo marcaron para toda su vida. La primera fue que, debido a que desde antes de nacer era cazador -como decía él- se llevó una honda de ligas con la que pasaba disparando a los pájaros, lo que provocó el repudio de los locales. Lo otro fue que al madurar las uvas en los extensos viñedos cercanos, un día tomó un racimo fuera de la cerca y se lo ofreció a sus

ISSN 0001-6002/2011/53/3/118-120

Acta Médica Costarricense, (C2011

Colegio de Médicos y Cirujanos compañeritos, quienes corrieron horrorizados dejándolo solo $\mathrm{y}$ gritando voleur..., voleur (ladrón).

Al regresar de Suiza asistió a la Escuela Buenaventura Corrales y posteriormente al Liceo de Costa Rica. Antes de graduarse como bachiller, y por sus altos ideales cívicos, aunados a su gran puntería con las armas, se alistó en las fuerzas costarricenses en la guerra contra Panamá, marchando

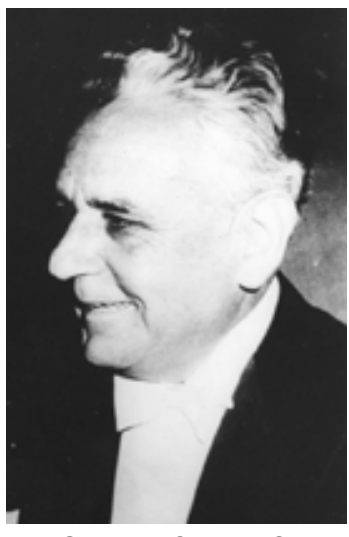

Dr. Gonzalo Cubero Otoya en el batallón dirigido por su profesor de inglés en el Liceo, don Miguel Ángel Dávila.

Después de graduarse viajó a París y se matriculó en la Universidad de La Sorbona. Según sus palabras, deseaba convertirse en un hombre universal, con conocimientos muy variados, y para ello decidió estudiar Derecho como primera profesión. Sin embargo, como en Costa Rica había gran número de abogados y también de farmacéuticos, su familia insistió que estudiara medicina en Bonn, ciudad más barata y con mejores profesores que París.

Aun sin hablar alemán, y gracias a que don Antonio Lehmann lo acompañó a hacer la matrícula, fue aceptado en esa universidad, aprobando a los pocos meses el examen de media carrera con la categoría de Bueno, algo excepcional para los extranjeros.

Con honores, el joven Cubero se graduó de médico y cirujano en la Universidad de Bonn el 8 de mayo de 1928, habiendo realizado su tesis sobre hemostasis. Enseguida debió buscar un hospital para hacer su Internado obligatorio, lo cual representó un gran problema, porque no deseaba separarse de su perro, un pastor suizo de color negro que era su permanente compañero. El único hospital que lo aceptó con su mascota Arno, fue el de Eltville Rhein, donde la gente rural estaba acostumbrada a los perros.

En el Hospital Municipal de Eltville junto al Rin, hizo el internado con el célebre cirujano Wilhem Welty, quien le tomó gran cariño, no solo por su sólida preparación médica, sino porque al igual que don Gonzalo, el profesor Welty era un consumado cazador.

Ya se dijo que el futuro doctor Cubero aprendió a utilizar armas de fuego desde niño, pues con frecuencia iba de 
cacería a Guanacaste, impresionante coto de caza en aquellos principios del siglo XX. Durante toda su vida, los caballos y la caza serían dos de sus grandes pasiones. Sus recorridos por el territorio nacional y sobre todo sus safaris a África lo hicieron famoso, pero quizá lo que más le agradaba contar era su primera cacería en Alemania, durante su internado.

Dado que el Profesor Welty era un reconocido tirador, una mañana de invierno lo invitaron con premura a ir tras una manada de jabalíes que acababa de entrar a un bosque nevado. Se precisaba salir enseguida si se deseaba obtener algunas presas, porque la manada no duraría mucho en el bosque.

Por estar en una emergencia médica, su jefe invitó a don Chalo para que tomara su sitio. Sin embargo, las cacerías eran muy formales y las personas eran colocadas en orden de jerarquía. Por lo tanto, al joven español, como lo llamaron, lo pusieron de último en la fila, junto a los espantadores que debían sonar latas y tarros para asustar la manada. En el sitio que le designaron, las posibilidades de obtener una presa eran prácticamente nulas. Pese a ello, el doctor Cubero no se amilanó y se propuso estar listo por si la manada aparecía de un momento a otro.

Cuando menos lo esperaba el grupo de cazadores, los animales salieron corriendo del bosque a gran velocidad y el joven Cubero disparó tres balas durante la centésima de segundo que los tuvo enfrente. Delante de él quedó tendida una cerda. Sin embargo, el macho que los dirigía se escapó por la colina nevada. Pese a ello, y estando seguro de que le había pegado al menos uno de los otros dos tiros, el doctor Cubero insistió ante el incrédulo jefe de la cacería, para que revisara si el animal iba herido. A desgano, por deber desplazarse por la nieve a menos de veinte grados centígrados, el jefe lo hizo y, al comprobar sangre, montó una organización para perseguirlo. Lo que no fue necesario porque, tendido a lo lejos en la siguiente hondonada, yacía el gigantesco verraco que dirigía la manada. Eso dejó admirados a los concurrentes, pero sobre todo, lo que los impresionó fue que debido a los rastros de sangre, el doctor Cubero detalló la entrada de la bala en el cuerpo del animal.

Al final de la cacería, consagrado entre los asistentes, el doctor Cubero mostró dos trofeos en su sombrero de caza: sendas ramas de pino.

Don Chalo casó en Alemania con la dama alemana doña Agnes Hammfetïn, a quien conoció un 15 de septiembre durante una fiesta de independencia en nuestra embajada. Con ella no tuvo hijos. Doña Agnes fue su fiel compañera y murió antes que él. Ella era una mujer muy culta y una destacada cazadora, con puntería igual o mejor que la de don Gonzalo, y juntos visitaban todos los grandes cotos de caza dentro y fuera del país.

Luego de terminar su carrera de medicina, ya casado, volvió a Costa Rica en 1929 y se incorporó al Colegio de

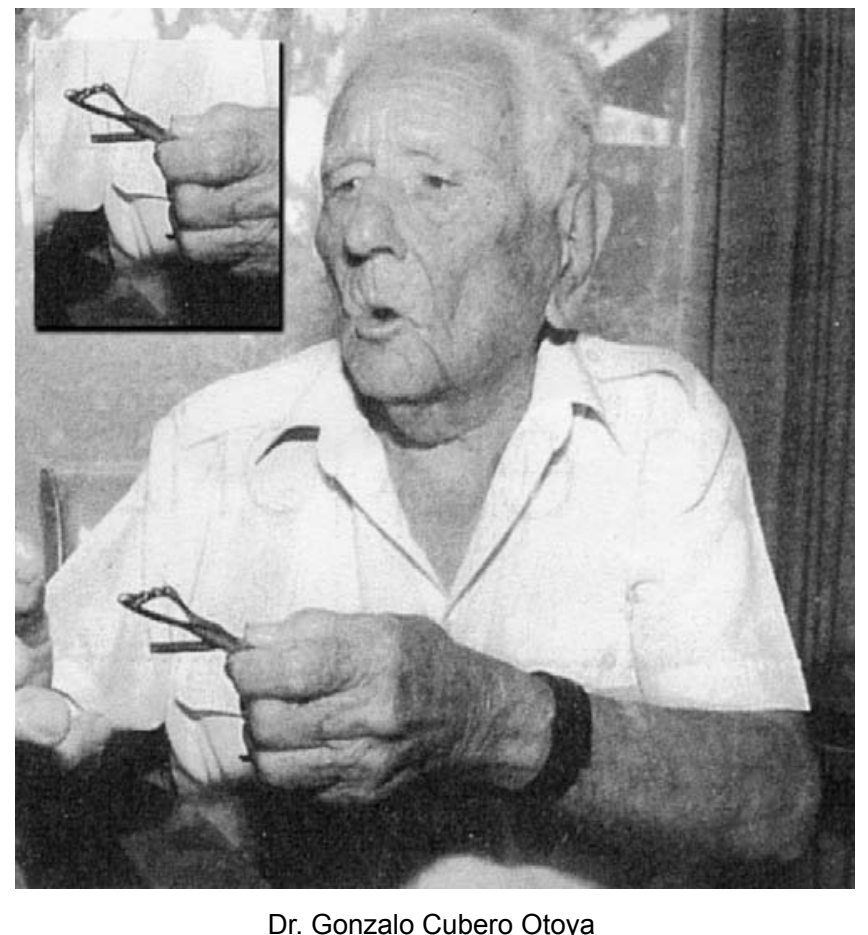

Médicos y Cirujanos. Posteriormente, regresó a Alemania en 1935 para estudiar cirugía. Al terminar su especialidad quirúrgica visitó en Nueva York al eminente cirujano Gustave Aufriech, quien en aquel tiempo realizaba fenestración del canal semicircular en un solo tiempo.

El primer trabajo del doctor Cubero en Costa Rica fue como médico benévolo (ad honorem) en el Hospital San Juan de Dios, debido a que el doctor Rafael A. Calderón Muñoz no encontró una plaza disponible para él. Ahí, para entretenerse, comenzó a ayudar a los enfermeros a bañar pacientes en el Servicio de Ortopedia, a cargo del doctor Ricardo Moreno Cañas.

Luego se incorporó al Servicio de Otorrinolaringología, con los eminentes cirujanos Constantino Herdocia y Antonio Facio. Años después, el doctor Cubero llegó a ser el tercer Jefe de ese Servicio y posteriormente fundó la Asociación Panamericana de Otorrinolaringología y Cirugía de Cabeza y Cuello.

Sus grandes inquietudes lo llevaron a incursionar en el campo de la cirugía plástica y reconstructiva, realizando las primeras rinoplastías en el país. En 1948 fundó el Servicio de Cirugía Reconstructiva en el Hospital San Juan de Dios, el cual lleva su nombre. Fue socio fundador de la Asociación Costarricense de Cirugía Plástica y también presidente del Colegio de Médicos y Cirujanos.

El doctor Cubero perteneció a la generación de médicos del Hospital San Juan de Dios que inició la medicina científica y llenó de luz el ámbito nacional, y debe decirse que sus inventos en las emergencias eran impresionantes, pudiendo señalarse, ante una fractura del maxilar superior, 
su idea de fijar dicho maxilar a los arcos cigomáticos. También impresionaba la enorme cantidad de bocios que operaba con anestesia local y es importante mencionar que cuando casi nadie en el país se atrevía a intervenir los casos de labio leporino y de paladar hendido, el doctor Cubero empezó a hacerlo con gran éxito, y junto con el doctor Paul Hollinger, de Chicago, realizó numerosas publicaciones.

Como aviador, el doctor Cubero inició sus clases en Frankfurt, porque desde joven, un poema que sabía de memoria lo hacía querer volar. Los versos que lo motivaron a convertirse en aviador son los siguientes:

Mariposa, tú y yo somos pequeños.

Menguados son mis sueños y tus alas.

Tú que puedes volar, no tienes sueños,

y yo, que puedo soñar, no tengo alas.

Él era tan metódico que durante la primera clase de aviación hizo treinta $\mathrm{y}$ dos despegues $\mathrm{y}$ aterrizajes. Al finalizar le preguntó al instructor cómo lo había hecho, y este le contestó que desde el despegue número doce él había sido simplemente su copiloto.

El doctor Cubero consiguió aterrizar en gran cantidad de playas de nuestro litoral, adonde en aquellos tiempos era imposible llegar. Quizá lo más maravilloso era que como buen amante de la poesía, cuando se encontraba suspendido entre cielo y tierra y rodeado por el maravilloso azul, soltaba el timón de su avioneta y declamaba Vuelo supremo, de Julián Marchena, la poesía de los aviadores costarricenses. También declamaba de memoria en varios otros idiomas.

Durante toda su vida, el doctor Cubero fue amigo íntimo del doctor Ricardo Moreno, y juntos operaron a Beltrán
Cortés, el asesino de los médicos Carlos Manuel Echandi Lahman y Moreno Cañas, en una misma noche. El psicópata iba también en búsqueda del doctor Cubero, quien había sido el anestesista durante esas operaciones. Por fortuna, él se salvó y no llegó a formar un trío fatídico de médicos en aquella oportunidad.

Al doctor Cubero le encantaba jinetear en las fincas Chapernal y Zapotal, que tenía con sus hermanos, y ya viejo, aún después de haber perdido parte de una extremidad, disfrutaba de cabalgar sus excelentes bestias pura sangre.

A los noventa y cinco años, el doctor Cubero mantenía una lucidez impresionante y era capaz de narrar sus experiencias médicas y personales, a pesar de la disminución de su capacidad auditiva.

Don Chalo falleció de casi cien años, el 12 de enero de 2003, y su vida estuvo llena de grandes logros por ser tan polifacético. Su carrera médica fue brillante y constituye un ejemplo para las juventudes presentes y futuras.

Para terminar, citamos otros de los versos que declamaba frecuentemente: Señor, dame valor, dame paciencia, y aunque mi vida sea de ayuno y penitencia, no me quites el corazón, la razón ni la conciencia...

\section{Dr. Rafael Jiménez Bonilla \\ Miembro del Comité Editorial de Acta Médica Costarricense}

Dr. Alfonso Durán Forn

Servicio de Hematología, Hospital San Juan de Dios 